\title{
Adapting PRISMA for Software Development in Rural Areas: A Mobile-based Healthcare Application Case Study
}

\author{
Siang-Ting Siew ${ }^{1}$, Alvin W. Yeo ${ }^{2}$ \\ ${ }^{1}$ Faculty of Computer Science and Information Technology \\ ${ }^{2}$ Institute of Social Informatics and Technological Innovations (ISITI-CoERI) \\ Universiti Malaysia Sarawak \\ Kota Samarahan, Sarawak, Malaysia \\ s.siangting@gmail.com, alvin@isiti.unimas.my
}

\begin{abstract}
This paper reports on the use of a proposed methodological framework called PRISMA (Participatory Action Research in Software Development Methodology Augmentation) to support and design a mobile-based healthcare application for a remote Penan community in Malaysian Borneo. PRISMA employs participatory action research (PAR). The approach has been successfully applied in projects with rural communities. The intent of PRISMA is to strengthen community participation and local management in order to ensure software system is built at interest of community. The healthcare application is targeted at young school-children and mothers as they have a major influence on health issues affecting their family. A key aspect of PRISMA is the active participation of multiple stakeholders - in our case, the villagers, medical doctors, researchers as well as teachers, who will be assisting in the monitoring of the usage and health change process for the children. Preliminary results of the health intervention will be reported.
\end{abstract}

Keywords-software development methodology; participatory action research; rural applications

\section{INTRODUCTION}

The United Nations Economic and Social Commission for the Asia Pacific [1] studied over 12,000 telecentres across 17 countries in Asia Pacific region (see Fig 1). The Commission showed that telecentres are used to access information for rural development such as education, agriculture and fisheries, e- health and providing e-government service. These types of usages do not only require connections to the rural community with Internet through modern infrastructure and hardware but also good quality software to uncover these rural communities' information that has been largely hidden from the existing information flow. Good quality software builds on good users' requirements that are based on their needs and conditions. Good quality software can eventually support and improve the living standard of a community. Thus, it is essential for a telecentre to act as a knowledge hub and network by providing appropriate software for its rural users. The term "appropriate software" indicates a platform offering the right information that is customisable for local relevance (such as language, extent of local creation content, connection mode, literacy level) and which is usable and meaningful within the community.

To create a successful telecentre community participation is a critical [2-3]. Getting community's active participation in the process will help to improve the likelihood of success in the project. Our hypothesis is that by employing participatory action research, it is possible to find a mode of working that supports the creation of useful and relevant software systems, which can contribute to rural development; and that will help the rural community to develop their future capacity to innovate and sustain information and communication technologies (ICTs) after completion of a project.

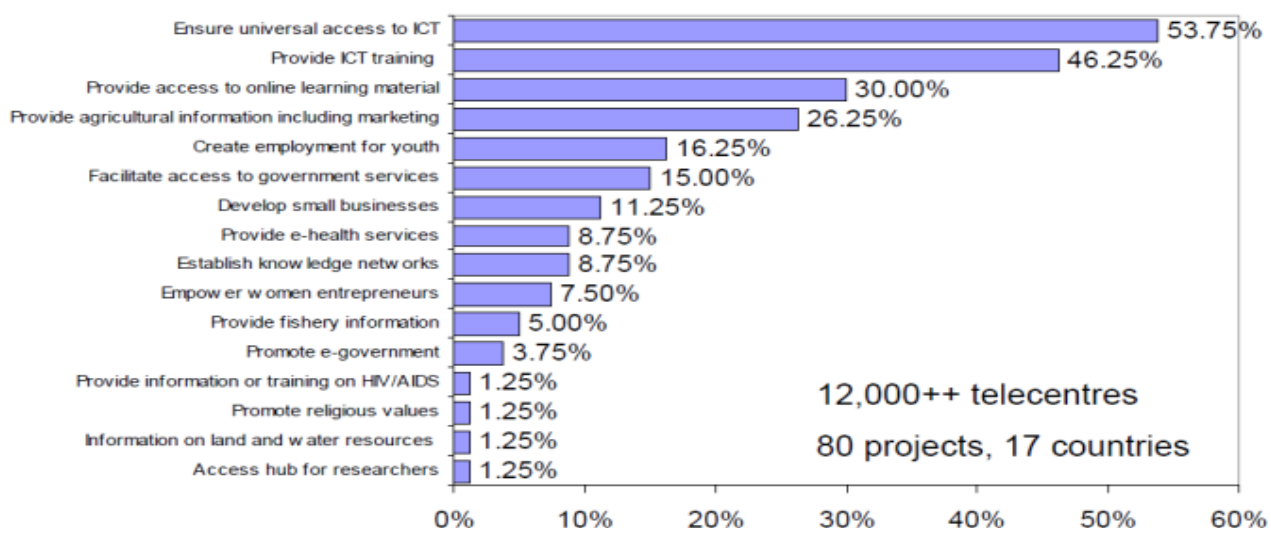

Figure 1. Distribution of telecentre usage [1] 